\title{
Physical Condition Test On Badminton Players Ages 10-12 Years Based On Android Smartphone Application
}

\author{
Agus Wiyanto ${ }^{1}$, Tandiyo Rahayu ${ }^{2}$, Sulaiman ${ }^{3}$, Taufiq Hidayah ${ }^{4}$ \\ \{AgusWiyanto7@gmail.com ${ }^{1}$ tandiyorahayu@mail.unnes.ac.id ${ }^{2}$, \\ sulaiman@mail.unnes.ac.id ${ }^{3}$, taufiqhidayah@mail.unnes.ac.id $\left.{ }^{4}\right\}$ \\ ${ }^{1}$ Universitas PGRI Semarang Indonesia, ${ }^{2}$ Graduate School, Universitas Negeri Semarang, Indonesia
}

\begin{abstract}
Physical condition test for the 10-12 years old badminton players is able to be taken through the aid if its measurement device fits with the badminton sport characteristic in order to produce players' improvement portfolio. This research aimed to discover the 10-12 years old badminton players` physical condition by using digital techology in form of android smartphone application. The research steps through physical condition test measurement covering the muscle strength, cardiovascular stamina, muscle power, speed, flexibility, balance, agility, coordination, precision and reaction is using android smartphone application. The research findings on physical condition measurement test process for the 10-12 years old badminton players can be conducted by using android smartphone application and able to produce their portfolio. The research conclude that badminton's coaches/practitioners are recommended to use physical condition test for the 10-12 years old badminton players through android smartphone-based application as the aid to discover their players/ trainees.
\end{abstract}

Keywords: Physical Condition Test, the 10-12 Years Old Badminton Players, Android Smartphone Application

\section{Introduction}

Badminton is a type of sport that played using racket, net, and shuttlecock with various of hitting technique beginning from relatively slow to the very fast together with tricky movement [1], [2]. Badminton is characterized as a fast sport which demand players to have physical quality, technical, tactical, and good mentality in order to win the tournament [3].

The optimal performance in badminton can be achieved if coaching program is done since the early of age. The badminton players start to train from the age of 10-12, followed by directing them for specialization at the age of 14-16 and expectedly able to reach their peak performance at the age of 20-25 [4]. Training program that given to the players are advisable be adjusted with the characteristic of badminton in order to improve their physical and technical component.

At the age of 10-12, physical as well as technical components that given for the players are recommended to be adjusted with the character of badminton in order to reach the optimal result at the next steps. As for physical component which relate with badminton covers: hand muscles strength, cardiovascular stamina, muscle power, speed, flexibility, balance, agility, coordination, precision and reaction. 
The appearance of a player are interaction between several factors such as technique, tactic, physic, and [4]. The good physical condition will brings player's performance to reach the maximum result because it connect with their training intesity process to sharpen their competence, with the result also able to influence them when joining some competition or championship event [5], [6]. The high performance can only be reached through the planned and structured training and it is done with the range of supervision and guidance from coach [7]. Performing the training of competence development needs a good quality of physical condition in order to reach a maximum result and able to support the technique in badminton game.

The physical condition measurement process is divided into two muscle groups namely: (1) upper extremity used for hitting activities in badminton that covers coordination, power, explosiveness, and reaction [8], [9]. The need of upper extremity can be measured by using wall badminton test [10]-[12]; push up [13]; and medicine ball [14], [15]; (2) lower extremity used for mobilizing the locomotor and non-locomotor movements in badminton footwork that covers agility, endurance, explosiveness, strength and speed [16]-[18]. The need of lower extremity can be measured by using multi stage fitness test, 12 minutes running, $20 \mathrm{~m}$ sprint, vertical jump, leg dynamometer [19].

The norm and physical condition test needs to be made that adjust with the physical condition for the 10-12 years old badminton players. Through the norm and physical condition test for the 10-12 years old badminton players, the physical condition measurement in todays digital and technology era can be developed by way of application to obtain the data taken from the training progress, in which able to facilitate the coaches in identifying their training program weaknesses given to the players. The physical condition factors that influence the badminton players' performance such as: leg muscle power, strength, flexibility, agility, balance, reaction speed, speed, cardiorespiration [20].

The digital and technology era is very helpful for the world of badminton, in which the training process, talent scouting, constructing or measurement process for the players/athletes can be monitored well. The application is made by considering the badminton characteristics, simple, appropriate, and suitable in order to give an exact solution. Android smartphone application is made to discover the physical condition of the 10-12 years old badminton players, so that hopefully be useful for the coaches and players/athletes in order to know their physical condition level.

\section{Method}

This research aimed to develop and validate a product for enhancing and improving a standard of quality effectively. The steps were covering: (1) Collecting information on the field through pre-liminary research. A pre-liminary research was conducted through reviewing the literature and observating several clubs of badminton to discover the real situation. (2) Analyzing the collected information. The researcher focused on the research problems and concluded the problems that existed on the location in term of physical condition, integrated motoric towards training process. (3) Conducting an initial development product of physical condition test for the 10-12 years old badminton players. (4) Validation from experts including: Expert 1 (academician), Expert 2 (coach), Expert 3 (practitioner), Expert 4 (technology). In this process, the experts assessed and gave their input on the initial product. Based on the input received, the initial product was being revised. 
Further to the step (5) was conducting a small-scale field trials on the initial product of the badminton players and was documented. The documentation contained of physical condition test implementation which were then observed by the experts. The inputs in this step were used as revision materials. (6) Conducting a large-scale field trials of physical condition test for the 10-12 years old badminton players which was documented. In this process, the experts gave their inputs once more as a substance of revising product for the main-scale field trials. (7) Conducting a main-scale field trials of physical condition test for the 10-12 years old badminton players which was also documented. In this process, the result of the data of physical condition test for the 10-12 years old badminton players were used for validation and reliability tests to develop the values and norms of physical condition test for the 10-12 years old badminton players. The next step was making a final product in form of manual book of the norm and physical condition test for the 10-12 years old badminton, then be followed by building an operating application into the android smartphone system that incorporate the test items and norms of physical condition test for the 10-12 years badminton players through the consultation with technology expert.

\section{Results and Discussions}

Physical condition test for the 10-12 years badminton players through android smartphone-based application could be developed if we have understand the characteristics of badminton and the components of physical condition that needed in badminton. One thing that causses the physical condition test was difficult to measure was because it needs the norms and physical condition tests for the 10-12 years badminton players which adjusted with badminton characteristic.

Test was an instrument that used to obtain personal information. The instrument could be in form of questions or interview, observation about physical performance, or observation about behaviour through checklists or anecdotal records. There were four terms that related with research concept used to foudn the learning success, namely measurement, examination, assessment, and evaluation [21]. The result of evaluation tests can be used to: 1) Predict the future performance; 2) Display the weakness; 3) Size of improvement; 4) Allow the coach/trainer to assess the success of training program; 5) Place the athletes into the appropriate training group; 6) Motivates the athletes [22].

The lack of physical condition tests understanding that adjusted and needed by the badminton players at the age of 10-12 years old would affect the development progress of the players, so that the preparation of the training program provided by the couch/trainer sometimes could not answer the needs of players. The physical condition tests for the 10-12 years badminton players consisted of players' physical condition, whic covers hand muscles, cardiovascular endurance, muscle power, speed, flexibility, balance, agility, coordination, precision and reaction.

The norms and physical condition tests were made to discover the level of the 10-12 years badminton players" physical condition while measuring process through android smartphonebased application. Physical condition measurement was adjusted based on the needs of the 10 12 years badminton players which consisted of players ' physical component, so that the output from the smartphone application was suited with players' needs. The improper used of assessment instruments would affect the success level of assessment because it could not measure the assessed object precisely [23]. 
The norm was made as a benchmark of the range of values that became the output of the application used. The application itself consisted of physical condition components which were designed based on the needs of the 10-12 years badminton players. The final result of the application were in form values that useful as a manual assessment or portfolio for the coach/or trainer. The physical condition tests for the 10-12 years badminton players which based on the android smartphone application can be used if it was supported by supporting factor like the device used to take the data of players' physical condition tests. The step in taking the data was in form of physical condition test that had been determined then be followed by deciding the norms of the physical condition tests. Generally, the physical condition was consisted of cardiorespiration endurance, muscle strength, durability, flexibility, and body composition which was an important part of physical growth [24]. The test components that existed in the android application was including physical condition test components of the 10-12 years old badminton players which has been adjusted based on the badminton characteristic.

The physical condion tests for the badminton players between 10-12 years old, which based on android smartphone application was effective to be used, it could be simply used, saving more time and energy, making the implementation process easier, the test results was more accurate and directly detected the players" data and save it into portfolio, so that the coach/trainer would not face any problems in giving the next training program. From each items in the application were the physical condition components which the data could be input directly when the player wanted to do the test, so this device could be very helpful to see the track record taken from their trainings.

The result of the tests was helpful for the badminton couches and players/athletes during the training or such an activity of developing movement competence to improve the skills or physical conditio. A player who has less physical condition in playing badminton should be given more training and adjusted based on his/her needs. The tests result can be used as portfolio of players' development competence.

\section{Conclusion}

Physical condition test for the 10-12 years badminton players through android smartphone-based application is used to obtain an assessment of their physical condition. The researcher suggests that the result of this development research can be used as one of an alternatives to test the badminton players " physical condition with those between 10-12 years old. 


\section{References}

[1] B. Xu, "The Role of Physical Training in Badminton Teaching," no. Cmes, pp. 285287, 2015.

[2] T. Grice, Badminton Steps to Success, 2nd ed. United States: Human Kinetics, 2007.

[3] A. Jacob, W. N. Wan Zakaria, and M. R. Bin Md Tomari, "Implementation of IMU sensor for elbow movement measurement of Badminton players," in 2016 2nd IEEE International Symposium on Robotics and Manufacturing Automation, ROMA 2016, 2016.

[4] T. O. Bompa and G. H. Gregory, Periodization Theory and Methodology of Training, Fifth. United States: Human Kinetics, 2009.

[5] G. A. Milon, "Study Regarding The Complexity Of Physical Training In Badminton," Gymn. Sci. J. Educ., 2014.

[6] J. Singh, S. Raza, and A. Mohammad, "Physical Characteristics and Level of Performance in Badminton: A Relationship Study," J. Educ. Pract., vol. 2, no. 5, pp. 6-10, 2011.

[7] M. Sudaryoto, T. Rahayu, and S. Rahayu, "Model Penilaian Kemampuan Bermain Sepakbola dalam Small Side Game bagi Pemain Usia Muda Abstrak," J. Phys. Educ. Sport., vol. 6, no. 1, pp. 72-75, 2017.

[8] C.-F. Hsieh, W.-H. Lin, J.-S. Chen, and C.-F. Hsieh, "Predicting the Biomechanics Effects on the Human Arm of the Badminton Forehand Smash," in The 14th IFToMM World Congress, 2015.

[9] Y.-C. Hsueh, Y.-Y. Chen, K.-M. Pan, and C.-L. Tsai, "Biomechanical Analysis of Badminton Forehand Net Shots," in 30th Annual Conference of Biomechanics in Sports, 2012.

[10] F. A. Miller, "A badminton wall volley test," Res. Q. Am. Assoc. Heal. Phys. Educ. Recreat., 1951.

[11] H. Abdi, A. Hajighasemi, and S. M. Tayebisany, "A comparison of posterior wall thickness, interventricular septum thickness and relative wall thickness of left ventricle of heart in male athletes (badminton and karate) and non-athletes," Br. J. Sports Med., 2010.

[12] J. L. Arias and F. J. Castejón, "Review of the instruments most frequently employed to assess tactics in physical education and youth sports.," J. Teach. Phys. Educ., vol. 31, no. 1974, pp. 381-391, 2012.

[13] J. W. Youdas, B. D. Budach, J. V. Ellerbusch, C. M. Stucky, K. R. Wait, and J. H. Hollman, "Comparison of muscle-activation patterns during the conventional push-up and perfect-pushupTMexercises," J. Strength Cond. Res., 2010.

[14] E. G. Artero et al., "Reliability of field-based fitness tests in youth," Int. J. Sports Med., vol. 32, no. 3, pp. 159-169, 2011.

[15] J. E. Earp and W. J. Kraemer, "Medicine ball training implications for rotational power sports," Strength Cond. J., 2010.

[16] M. Phomsoupha and G. Laffaye, "The Science of Badminton: Game Characteristics, Anthropometry, Physiology, Visual Fitness and Biomechanics," Sports Medicine. 2014.

[17] L. Fu, F. Ren, and J. S. Baker, "Comparison of Joint Loading in Badminton Lunging between Professional and Amateur Badminton Players," Appl. Bionics Biomech., 2017.

[18] K. N. S. K. Syamimi, M. S. Salim, and N. Omar, "A biomechanical analysis of the 
knee during jump landing," 30th Annu. Conf. Biomech. Sport., 2012.

[19] ACSM, ACSM's Guidelines for Exercise Testing and Prescription. 2013.

[20] M. Suparmin, "Identifikasi Faktor Fisik Atlet Cabang Bulutangkis," vol. 15, no. 1, pp. $65-75,2015$.

[21] U. Nasution and S. Damanik, "Jurnal Ilmu Keolahragaan," vol. 15, no. 1, pp. 85-98, 2016.

[22] B. Mackenzie, 101 Performance Evaluation Tests, 2nd Altern. Green Star Media, 2015.

[23] L. D. Patri, Sukestiyarno, and Rumini, "Instrumen Penilaian Lompat Jauh Berbasis Rolling Assessment Dalam Pembelajaran Penjasorkes Smp,” J. Educ. Res. Eval., vol. 3, no. 2, pp. 36-40, 2016.

[24] Z. Zhu, Y. Yang, Z. Kong, Y. Zhang, and J. Zhuang, "Prevalence of physical fitness in Chinese school-aged children: Findings from the 2016 Physical Activity and Fitness in China-The Youth Study,” J. Sport Heal. Sci., vol. 6, no. 4, pp. 395-403, 2017. 